\title{
Determination of selective stimulus control by part of a compound $\mathbf{S}^{\Delta^{\prime}}$
}

DANIEL F. JOHNSON, BILL N. KINDER, and GIENN N. SCARBORO, Virginia Polytechnic Institute, Blacksburg, Va. 24061

Eight White King pigeons were trained to peck at each of four stimuli presented alone: white vertical line, white horizontal line, red background, green background. Then each pigeon was given 10 sessions of single stimulus discrimination training and 5 sessions of compound stimulus discrimination training with these stimuli; four pigeons received single stimulus training first and four received compound stimulus training first. Vertical line and green background were always $S^{D}$ components, and horizontal line and red background were always $S \Delta$ components. In generalization tests, when all fotir stimuli were again presented alone, nonresponding was selectively controlled by the single stimulus discrimination training, $s \Delta$, regardless of training sequence.

Selective stimulus control of responding by a single component of a compound stimulus correlated with reinforcement has often been demonstrated, e.g., Lashley (1938), Reynolds (1961). Reynolds trained two pigeons to discriminate a white triangle on a red background from a white circle on a green background. When these four stimuli, including the two $S \Delta$ components, were presented alone in an extinction test, one $S$ responded only to the red background and the second $S$ responded only to the white triangle. Johnson \& Cumming (1968) recently demonstrated control of selection among components of a compound stimulus by training a discrimination between single components separate from their appearance in a compound stimulus discrimination.

In these experiments, selection occurred with respect to components of positive compound training stimuli. Since responding to $S^{\Delta}$ components was essentially zero, it would appear that nonresponding was nonselectively controlled by components of the negative compound training stimuli. However, without prior measure of response strength to each stimulus component, it is impossible, as Eckerman (1967) pointed out, "...to determine whether this non-selective control reflects a reduction of response strength in both components or the mere absence of response strength to these two stimuli [p. 299]."

Eckerman (1967) trained three pigeons to peck at each of four stimuli alone before repeating the essential conditions of the Reynolds experiment. Compound stimulus discrimination training employed a white vertical line on a green background as $\mathrm{SD}$ and a white horizontal line on a red background as $s \Delta$. When these four components were again presented alone in an extinction test, nonresponding by at least one $\mathbf{S}$ during the test was selectively controlled by the red background.

The present experiment obtained prior response measures to four stimulus components, then trained a single stimulus

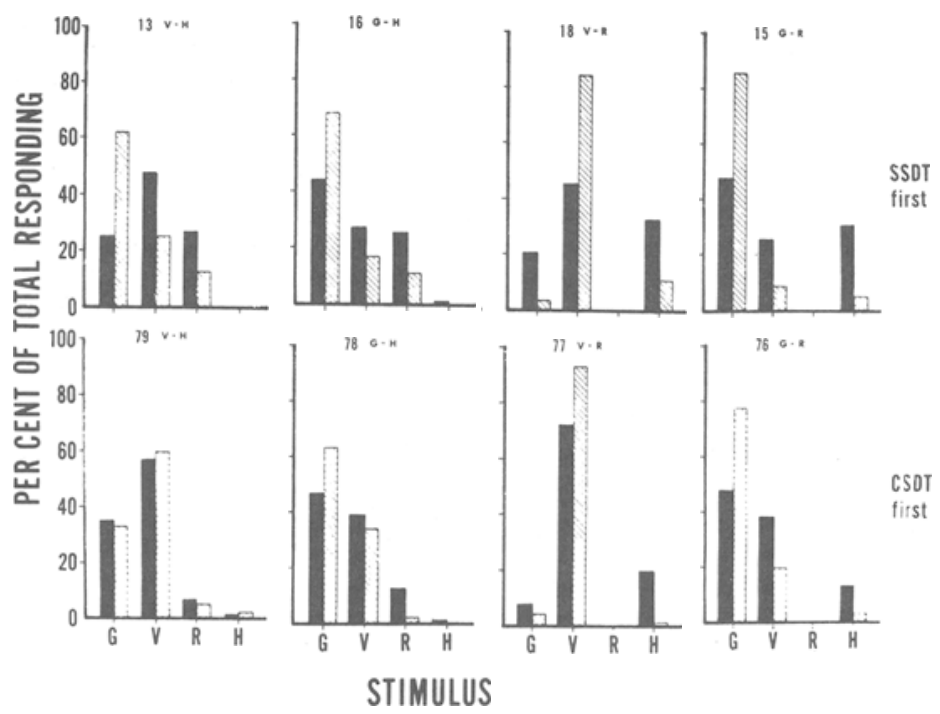

discrimination either before or after a component stimulus discrimination using the four stimuli.

\section{SUBJECTS}

Eight 5- to 6-year-old White Carneau and White King cock pigeons were maintained at $80 \%$ free-feeding body weights and were experimentally naive at the outset.

\section{APPARATUS}

A standard pigeon operant chamber (LVE 1519) had a single pecking key which could be transilluminated from behind by an IEE display unit. The automatic feeder presented grain ( $50 \% \mathrm{Kaffir}, 40 \%$ vetch, $10 \%$ hempseed) for 4-sec periods. White noise (86-dB SPL) through the chamber speaker masked extraneous laboratory sounds and a houselight provided general illumination.

$$
\text { PROCEDURE }
$$

Key-pecking for each $S$ was established to a white, fully lighted key, and maintained on a random-interval schedule of reinforcement having a mean interreinforcement interval of 1 min (RI 1; Farmer, 1963) for three daily 1.h sessions. In $20-25$ subsequent, daily 1-h sessions, each of four stimuli-green background (G), red background (R), white vertical line (V), and white horizontal line (H), appeared alone, equally often, in mixed orders for 1-min periods. Colored backgrounds filled the key area and white lines were diameters 18 in. wide. Responses to each stimulus were reinforced on the RI 1 schedule. This initial training phase was terminated when, for any $S$, responses per session to each stimulus did not change more than $5 \%$ over five successive sessions.

All Ss were then given $101-\mathrm{h}$ sessions of single stimulus discrimination training (SSDT) and 5 1-h sessions of compound stimulus discrimination training (CSDT). Four Ss, S13, S16, S18, and S15, received SSDT before CSDT, and four Ss, S79, S78, $S 77$, and $S 76$, received the reversed sequence. For SSDT, each $S$ from each sequence was assigned one of the four possible combinations keeping vertical line and green background positive, and horizontal line and red background negative. SSDT discriminative stimuli were assigned as $\mathrm{SD}$ and $\mathrm{S} \Delta$, respectively, among $\mathrm{Ss}$ as follows: S13 and S79-vertical line, horizontal line; $S 16$ and $S 78$-green background, horizontal line; $\$ 18$ and S77-vertical line, red background; and S15 and S76-green background, red background. During CSDT, the missing components were added to form component

Fig. 1. Per cent of total responding in the two test sessions to each of the four stimuli for each $S$. Solid and striped bars indicate values from the first and second test sessions, respectively. 
discriminative stimuli of $S D$-vertical line on green background-and $S \Delta_{-}$horizontal line on red background. In discrimination training, responses to $S^{D}$ were reinforced on the RI 1 schedule, and responses to $S \Delta$ were never reinforced.

Following training, all four stimuli were again presented alone in mixed orders for two $1-h$ test sessions. Responses were recorded but never reinforced.

Any stimulus period in all phases lasted for $1 \mathrm{~min}$, and a 5 -sec "time-out" period intervened between stimulus poriods. In "time-out," the houselight remained on, but stimulus lights were off and responses were never reinforced.

\section{RESULTS}

Initial Training

During the 20-25 initial training sessions, "preferences" (portions of total-session responding greater than 25\%) and "avoidances" (portions of total-session responding less than 25\%) occasionally appeared but in no consistent pattern for any $S$ throughout the initial training phase. In the final five sessions, when response distributions stabilized within $5 \%$ of mean rates, approximately $25 \%$ of total session responding occurred to each stimulus, ranging from $19 \%$ to $32 \%$ for any stimulus in any session.

\section{Discrimination Training}

All but three Ss acquired both discriminations to precisions of less than $2 \%$ $\mathrm{S} \Delta$ responses within $5 \mathrm{~h}$ of exposure. $\mathrm{S} 15$ required $9 \mathrm{~h}$ on G-R SSDT to reach this level. S78 on G-H SSDT and S79 on V-H SSDT exhibited extremely high response rates (about 90 responses/min compared to a mean of about 40 responses/min for other Ss) and displayed minima of $12 \%$ and $25 \%$ $\mathrm{S} \Delta$ responding, respectively, during initial $\mathrm{CSDT}$ and $5 \%$ and $10 \% \mathrm{~S} \Delta$ responding respectively, during subsequent SSDT

In general, the discriminations were acquired with steady increments in precision of performance. Performances were about equally disrupted when the second discrimination training phase, whether SSDT or CSDT, was introduced, but performances returned to equal or greater precisions within $5 \mathrm{~h}$ exposure.

Test for Stimulus Control

Proportions of total responding in the two test sessions to the four stimuli for each $\mathrm{S}$ are presented in Fig. 1. Solid and striped bars indicate values from first and second test sessions, respectively. For Ss initially exposed to SSDT, the total number of responses ranged from 1035 to 1759 in the first test session. The greatest portion of responding, from $45 \%$ to $48 \%$, occurred in the presence of the component, which was $S^{D}$ in SSDT. Of principal interest, the least amount of responding, as much as $1 \%$ for only one $S$, occurred to the single $S \Delta$ of SSDT. Portions of test session responding to stimulus components added in CSDT were about equal. Portions ranged from $21 \%$ to $28 \%$ to the added $\mathrm{SD}^{\mathrm{D}}$ component and from $21 \%$ to $33 \%$ to the added $\mathrm{S} \Delta$ components.

For Ss initially exposed to CSDT, total responses in the first test session ranged from 1438 to 2938. Again, the greatest proportion, from $47 \%$ to $72 \%$, of test responding occurred to the SSDT $\mathrm{SD}^{\mathrm{D}}$, and, again, the least responding, as much as $1.8 \%$ for two Ss, occurred to the SSDT $\mathrm{S} \Delta$ Portions of test responding to the removed CSDT SD component ranged from $8 \%$ to $39 \%$ and portions of test responding to the removed CSDT $\mathrm{S} \Delta$ component ranged from $7 \%$ to $14 \%$.

In general, responding during the second test session showed sharpening of the stimulus control observed in the first test session. Except for S13, for which the $S^{D}$ component exercising primary control reversed, the SSDT $S D$ controlled even greater portions of responding in the second test session. And, except for S79, no other S responded to the SSDT $S \Delta$ in the second test session. All other components for all other Ss controlled smaller portions of test responding.

Extinction records from each stimulus component for each $S$ were generally smooth, negatively accelerated functions.

\section{DISCUSSION}

Initial training established approximately equal response strength to each of the four stimulus components. However, subsequent single stimulus training and compound stimulus training considerably altered the distribution of responses to stimuli. In particular, single stimulus training, regardless of whether it preceded or followed compound stimulus training, determined that stimulus control of responding was exercised primarily by the single stimulus training $S^{D}$ and stimulus control of nonresponding was primarily exercised by single stimulus training $S \Delta$.

Nonresponding was exclusively controlled by the SSDT $S \Delta$ for Ss initially exposed to SSDT. While virtually no responding occurred to SSDT $S \Delta$ in the cases that SSDT followed CSDT, the other component of the compound $S^{\Delta}$ nevertheless retained some control of nonresponding. In three of the four $\mathrm{Ss}$, response strength to the removed $S \Delta$ component was less than to the removed $\mathrm{S}^{\mathrm{D}}$ ) component. Thus, while the stimulus exercising primary control was determined by separate, single stimulus training, the effects of sequence were not preciscly equivalent for the present conditions. Johnson and Cumming (1968) obtained similar results with respect to determining control by parts of a compound $S \Delta$.

Kesponse strengths to the nonselected component of the $S^{D}$ compound were generally as high as strengths established in the initial training phase. This finding suggests that studies producing selective stimulus control by pretraining a single stimulus discrimination (cf. Johnson \& Cumming, 1968) operate to prevent the acquisition of control by subsequently added stimulus dimensions.

These findings are accountable with a theory which counts reinforcements and extinction time in stimulus components (Spence, 1936), but this type of theory is not generally satisfactory for findings of selective stimulus control (cf. Mackintosh, 1965). Rather, an additional, active mechanism is presumed to occur. The present results suggest that an active stimulus selection mechanism should be applied to negative, as well as positive, compound training stimuli.

\section{REFERENCES}

ECKERMAN, D. A. Stimulus control by part of a complex S $\Delta$. Psychonomic Science. 1967, 7, 299-300.

FARMER, J. Properties of behavior under random interval reinforcement schedules. Journal of the Experimental Analysis of Behavior, 1963, 6, 607-616.

JOHNSON, D. F., \& CUMMING, W. W. Some determiners of attention. Journal of the Experimental Analysis of Behavior, 1968, 11 , 157-166.

LASHLEY, K. S. The mechanism of vision: XV.Preliminary studies of the rat's capacity for detail vision. Journal of General Psychology, $1938,18,123-193$.

MACKINTOSH, N. J. Selective attention in animal discrimination learning. Psychological Bulletin, $1965,64,124-150$.

REYNOLDS, G. S. Attention in the pigeon. Journal of the Experimental Analysis of Behavior, 1961, 4, 203-208.

SPENCE, K. W. The nature of discrimination learning in animals. Psychological Review, $1936,43,427-449$.

1. Portions of these results were presented to the Eastern Psychological Association, Philadelphia, 1969. This research was supported by Grant MH-1 3383 from the National Institute of Mental Health and by NASA Grant NGR-47-004-006. Address reprint requests to Daniel F. Johnson, Department of Psychology, Virginia Polytechnic Institute, Blacksburg, Va. 24061. 